\title{
Correlation between Id Genes Expressions and Histological Grade, Sonographic Findings in Breast Cancer
}

Huijie Shi', Lei Zhang ${ }^{2}$, Yanjun Qu ${ }^{1}$, Lifang Hou ${ }^{1}$, Ling Wang ${ }^{1}$ and Min Zheng ${ }^{1 *}$

${ }^{1}$ The First Affiliated Hospital of Harbin Medical University, PR China

${ }^{2}$ Department of Pathology, Basic Medical, Harbin Medical University, PR China

\begin{abstract}
Objective To investigate the expression significance of inhibitor of DNA binding (Id)-1, Id-2 and Id-3 mRNAs in breast cancer patients, and explore the correlation between sonographic characteristics, histological grades and expressions of Id-1, Id-2 and Id-3 mRNAs.

Methods The expressions of Id1-3 mRNAs in 62 breast cancer patients and 49 normal controls were examined by using real-time fluorescent quantitative reverse transcription polymerase chain reaction (RT-FQ-PCR). The correlations between sonographic characteristics, histological grades and expressions of Id1-3 mRNAs were analyzed with one-way ANOVA.

Results: Id-1 and Id-3 mRNA were higher expressed in breast cancer patients than those in normal control cases (Id-1: $0.0141 \pm 0.01025$ versus $0.0075 \pm 0.00309, p=0.0001 ; \mathrm{Id}-3$ : $0.0139 \pm 0.01029$ versus $0.0078 \pm 0.00312$ $p=0.005$ ), while expression of Id-2 mRNA was lower (Id-2: $0.0195 \pm 0.01299$ versus $0.0275 \pm 0.01401, p=0.033$ ). Along with the increase in histologic grades, Id-1 and Id-3 mRNA expressions in breast cancer tissue showed an increase tendency, however, Id-2 showed an opposite expression pattern with Id-1 and Id-3. The expression of Id-1 was higher in patients with keloid-like and hyperechoic halo, while Id-3 mRNA was highly expressed in patients with keloid-like and peripheral catheter expansion under ultrasonography.
\end{abstract}

Conclusion: Expression levels of Id-1 to 3 mRNAs are highly correlated with histological grades and sonographic characteristics of breast cancer.

Keywords: Breast cancer; Inhibitor of DNA binding genes; Histologic grade; Sonographic characteristic

\section{Introduction}

Breast cancer is the most frequent malignant cancer and the second cause of cancer death among women in the United States. According to the statistics by the American Cancer Society, there were approximately 229,060 new cases diagnosed and 39,920 deaths from breast cancer worldwide in 2012 [1]. In China, the incidence of female breast cancer has also increased dramatically in recent years [2]. It is estimated that the incidence rate of breast cancer will be 85.3 per 100,000 women in China by year 2021 [3]. The mortality for breast cancer patients may be mainly attributed to their diagnosis in late phase and development of metastasis to other sites, leading to the resistant to most treatment modalities such as chemotherapy and radiotherapy [4-6]. Therefore, how to early diagnose the breast cancer is still an important topic in clinic.

Recently, greater attention is being paid to tumor molecular markers, including inhibitor of DNA binding (Id) protein. Id proteins, members of a family of helix-loop-helix (HLH), are suggested to promote cancer cells proliferation by regulating the activation of p16INK4a/pRB pathway [7]. Down-regulation of Id-1 and Id-3 inhibits mammary tumor-initiating capacity, induces cell apoptosis, and blocks breast cancer cells invasion in vitro and metastasis in vivo [811]. Compared to those with absent or low expression, breast cancer patients with strong or moderate Id- $1 / 3$ expression have a significant shorter overall and disease-free survival $[12,13]$. Thus, Id- $1 / 3$ genes have become important targets for therapeutic intervention of breast cancer [14]. The role of Id- 2 may be inverse with Id-1/3 genes because the Id-2 is lowly expressed in aggressive and metastatic breast cancer cells [15] and high Id-2 protein expression associates with a favourable prognosis in patients with primary breast cancer [16]. However, the tumor molecular markers can only be identified in histologic specimens which must be isolated from breast and may cause an injury in the function of breast. It is necessary to develop a non-invasive examination tool that is well correlated with tumor prognostic factors and can evaluate tumor biologic behavior and prognosis in vivo before surgery [17].

Compared with needle localization biopsy, image-guided breast biopsy via core needle biopsy has proven to be a more accurate and costefficient technique for sampling nonpalpable breast lesions, leading to favorable cosmetic results and few complications $[18,19]$. The mostly common imaging guidance system includes ultrasonography, magnetic resonance imaging (MRI) and mammography [20]. Currently, most investigators have focused on distinguishing benign from malignant breast masses using ultrasonography. However, correlation of ultrasonic characteristics with tumor molecular markers has rarely been reported [17]. This study was designed to analyze the ultrasonic characteristics of breast cancer and investigate the correlation between ultrasonic characteristics and Id genes expression in breast cancer using realtime fluorescent quantitative reverse transcription polymerase chain reaction (RT-FQ-PCR).

\section{Materials and Methods}

\section{Data source}

A total of 111 persons were enrolled in our study, including 62 breast

*Corresponding author: Min Zheng, The First Affiliated Hospital of Harbin Medical University, 23 Youzheng Street, Nangang District, Harbin, Hei Longjiang Province, PR China, Tel: 864518666 1458; E-mail: zhengmin_dc@126.com

Received January 15, 2014; Accepted February 27, 2014; Published March 01, 2014

Citation: Shi H, Zhang L, Qu Y, Hou L, Wang L, et al. (2014) Correlation between Id Genes Expressions and Histological Grade, Sonographic Findings in Breast Cancer. J Cytol Histol S4: 005. doi:10.4172/2157-7099.S4-005

Copyright: (c) 2014 Shi H, et al. This is an open-access article distributed under the terms of the Creative Commons Attribution License, which permits unrestricted use, distribution, and reproduction in any medium, provided the original author and source are credited. 
cancer patients and 49 normal controls, which were collected between January 2010 and September 2011. The average age of patients in our study was 51 years old (range, 28-57 years). According to the World Health Organization (WHO) criterion for histologic classification of breast cancer, the 62 breast cancer patients were grouped into different grades: 14 in grade I, 31 in grade II and 17 in grade III. All patients had no history of antitumor therapies before operation. Written informed consent was obtained from all patients and the protocol was approved by the Ethical Committee of the First Clinical College of Harbin Medical University in accordance with the Declaration of Helsinki.

\section{Ultrasonic inspection}

All of the enrolled patients were subjected to a Doppler ultrasonic diagnostic apparatus with a frequency of L12-5 linear array probes (8$12 \mathrm{MHz}$ ) for observation of keloid-like lesions, peripheral halo ring, calcification and peripheral catheter expansion.

\section{Real-time PCR}

Total RNA was extracted from cancerous or normal tissues using TRIZOL reagent according to the manufacturer's instructions (Qiagen kit). The concentration of total RNA was quantitated by using UV spectrophotometer (Parmacia-Bitech). The integrity of extracted RNA was verified by agarose gel electrophoresis. Total RNA was denatured at $70^{\circ} \mathrm{C}$ for $5 \mathrm{~min}$ and reverse transcription was performed in $18 \mu \mathrm{l}$ of $1 \times$ reverse transcriptase buffer [50 mM Tris-HCL (PH 8.3), $75 \mathrm{mM} \mathrm{KCL}$ and $3 \mathrm{mM} \mathrm{MgCl}_{2}$ ] with $0.5 \mathrm{mM}$ deoxynucleotide triphosphates and $1 \mu \mathrm{l}$ of RNasin. The Primer sequences were designed using the Primer Express software (PE Applied Biosystems) and listed in Table 1. PCR was conducted in $43 \mu \mathrm{l}$ of $1 \times$ PCR buffer [ $10 \mathrm{mM}$ Tris-HCL (PH8.4), $50 \mathrm{mM}$ $\mathrm{KCL}$, and $1.5 \mathrm{mM} \mathrm{MgCl}_{2}$ ] with $0.2 \mathrm{mM}$ deoxynucleotide triphosphates, $5 \mu \mathrm{l}$ of cDNAs, 2 units of Taq DNA polymerase (Promega), $0.4 \mu \mathrm{M}$ of sense and antisense primers. The cycling parameters were as follows: denaturation at $95^{\circ} \mathrm{C}$ for $5 \mathrm{~min}$, followed by 35 cycles of $95^{\circ} \mathrm{C}$ for 30 $\mathrm{s}, 62^{\circ} \mathrm{C}$ for $20 \mathrm{~s}$, and $72^{\circ} \mathrm{C}$ for $20 \mathrm{~s}$, and a final extension at $72^{\circ} \mathrm{C}$ for 10 min. Levels of $\beta$-actin mRNA was used as an internal control in our study. All reactions were performed in the ABI Prism 7000 Sequence Detection System.

\section{Statistical analysis}

The experiment data are expressed as mean \pm standard deviation (SD) of three duplicates, and analyzed with SPSS13.0 software package (SPSS Inc., Chicago, IL, USA). Measurement data were compared between groups using one-way ANOVA with post hoc tests (for multiple group comparisons). $P$ values $<0.05$ were considered statistically significant.

\section{Results}

Expressions of Id-1, Id-2 and Id-3 mRNA in breast cancer and normal healthy cases

Id-1 to Id-3 mRNAs showed a different expression pattern in breast

\begin{tabular}{|c|c|c|c|c|}
\hline Gene & $\begin{array}{c}\text { Amplified } \\
\text { fragment } \\
\text { (bp) }\end{array}$ & Primer sequences & $\begin{array}{l}\text { Annealing } \\
\text { temperature }\end{array}$ & $\begin{array}{l}\text { Fragment } \\
\text { position } \\
\text { (bp) }\end{array}$ \\
\hline \multirow{2}{*}{ Id-1 } & \multirow{2}{*}{705} & F : 5'-CAAGAATCATGAAAGTCGCCAGTG-3' & \multirow{2}{*}{62} & \multirow{2}{*}{$92-796$} \\
\hline & & R : 5'-CAGCTCCAACTGAAGGTCCCTG-3' & & \\
\hline \multirow{2}{*}{ Id-2 } & \multirow{2}{*}{511} & F : 5'-GGGAC GAAGGGAAGCTCC-3' & \multirow{2}{*}{60} & \multirow{2}{*}{$85-595$} \\
\hline & & R : 5'-CCGCTTATTCAGCCACACAG-3' & & \\
\hline \multirow{2}{*}{ Id-3 } & \multirow{2}{*}{461} & F: 5'-TCCTACAGCGCGTCATCGACTAC-3' & \multirow{2}{*}{61} & \multirow{2}{*}{$537-997$} \\
\hline & & R: 5'-TCACAGTCCTTCGCTCCTGAGC-3' & & \\
\hline
\end{tabular}

Table 1: Primer sequences of amplified gene cDNA. cancer and normal healthy ones. As shown in Figure 1, Id-1 and Id-3 mRNAs were higher expressed in the 62 breast cancer individuals than those in the 49 normal healthy controls (Id-1: $0.0141 \pm 0.01025$ versus $0.0075 \pm 0.00309, \mathrm{p}=0.0001$; Id-3: $0.0139 \pm 0.01029$ versus $0.0078 \pm$ $0.00312, \mathrm{p}=0.005$ ). However, expression status of Id-2 mRNA was opposite, whose expression was significantly lower in breast cancer patients (Id-2: $0.0195 \pm 0.01299$ versus $0.0275 \pm 0.01401, \mathrm{p}=0.033$ ).

\section{Relationship between histological grades and Id-1/3 mRNA} expression in the breast cancer

As expected, the expressions of Id-1 and Id-3 mRNA were gradually increased along with the increase in the histological grades in breast cancer tissues (Id-1: $p=0.0003$ between grade I and III; Id-3: $p=0.0005$ between grade I and III), while Id-2 showed an opposite expression pattern with Id-1 and Id-3 with the change in the histological grades (Id-3: $p=0.0019$ between grade I and III) (Figure 2).

\section{Relationship between ultrasonography and Id1-3 mRNA expressions in breast cancer}

Furthermore, we also analyzed the expressions of Id-1, Id-2, and Id-3 according to the ultrasonic results in the breast cancer patients (Figure 3). As a result, Id-1 mRNA was highly expressed in breast patients with a keloid or hyperechoic halo under ultrasonography than patients without a keloid $(\mathrm{p}=0.0013)$ or hyperechoic halo $(\mathrm{p}=0.0084)$. The expression of Id-3 mRNA was significantly higher in breast patients with a keloid $(\mathrm{p}=0.0004)$ and peripheral catheter expansion $(\mathrm{p}=0.0003)$ under ultrasonography (Figure 4). No significant difference in Id-2

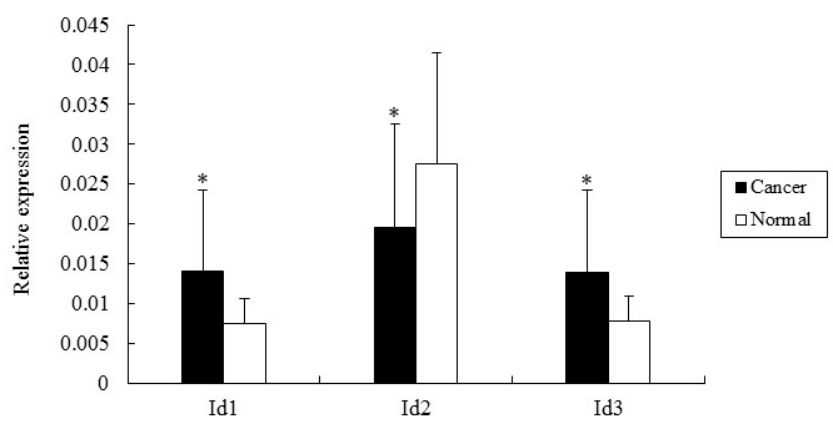

Compared with normal control, $\mathrm{p}<0.05$

Figure 1: Id-1, Id-2, and Id-3 mRNAs expressions in the breast cancer individuals and normal healthy controls.

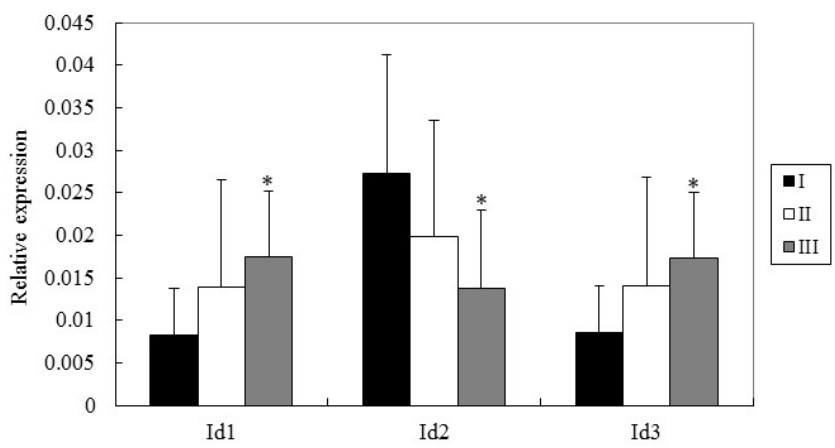

Compared with grade $\mathrm{I}, \mathrm{p}<0.05$.

Figure 2: The association between Id-1, Id-2, and Id-3 expressions, and the histological grades of breast cancer tissues. 
expression was observed between patients with the following ultrasonic findings, keloid, hyperechoic halo, posterior acoustic attenuation, microcalcification or peripheral catheter expansion and patients without.
A

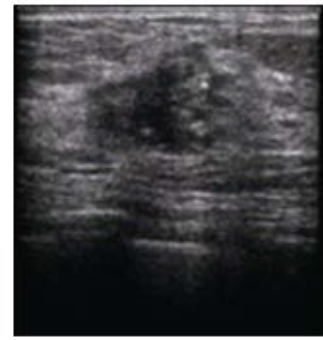

C

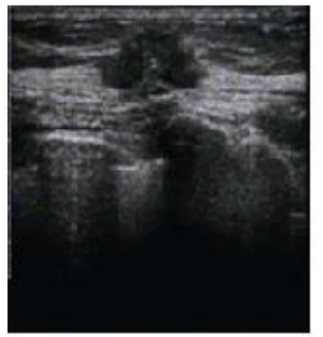

B

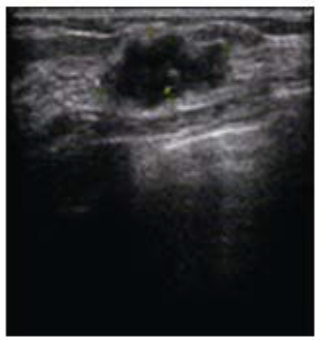

D

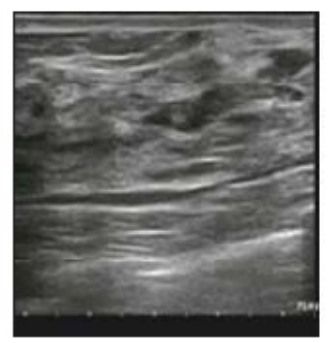

Figure 3: Ultrasonic characteristics of breast cancer patients. (A). No envelope around the breast lump and keloid-like grows into the surrounding tissues; (B). Hyperechoic halo appears around breast lumps; (C). Psammomatous calcifications in the lumps. (D). Peripheral catheter expansion in breast cancer patients.

\section{Discussions}

Our present study demonstrated that Id- 1 and Id-3 genes were higher expressed, but Id-2 gene was lower expressed in breast cancer patients compared with normal healthy controls. According to previous studies, the high expressions of Id-1 and Id-3 may cause breast cancer cells proliferation, invasion, and metastasis, resulting in poor prognosis $[8,9,12]$. These conclusions may also be indirectly proved by our study because we found that the expressions of Id-1 and Id-3 mRNA were much higher in grade III than those in grade I $(p<0.05)$. According to the microscopic similarity of breast cancer cells to normal breast tissues [21], the breast cancer was classified into well differentiated (grade I), moderately differentiated (grade II), and poorly differentiated (grade III) types. The poorly differentiated breast cancer cells have a stronger metastasis potential and indicate a poor prognosis. More importantly, it has been reported that Id- 1 and -3 have the ability to inhibit cellular differentiation $[22,23]$.

Ultrasound is a widely used modality for diagnosing breast cancers, with the sensitivity and negative predictive value of $98.4 \%$ and $99.5 \%$ [24]. Previous studies have suggested that there are correlations between ultrasonic findings and prognostic indicators for breast cancers. For example, Kim et al. have demonstrated that a hypoechoic or complex echo pattern is more often displayed in cancers with negative estrogen or progesterone receptor. HER-2/neu positive cancers have more calcifications [25]. Cao et al. have showed that centripetal enhancement is common in tumors with negative estrogen receptor expression; perfusion defect can be seen in tumors with positive c-erb-B2 expression, positive Ki-67 expression and larger tumor diameter [17]. In this study, we investigated the correlation between Id genes expression and specific ultrasonic characteristics, including keloid, hyperechoic halo, posterior acoustic attenuation, microcalcification or peripheral catheter expansion. To our knowledge, this was not
A

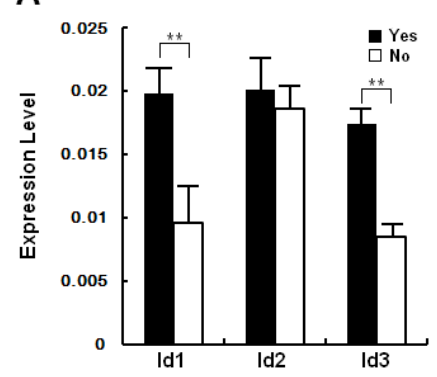

B

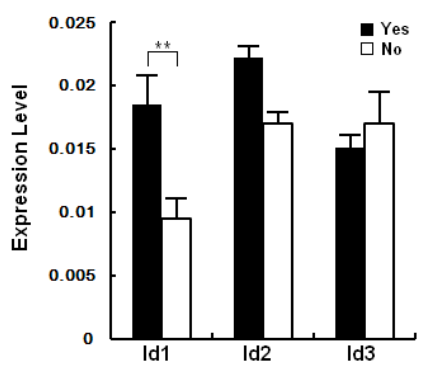

C

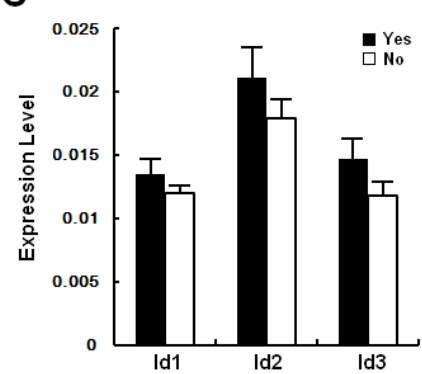

D

E
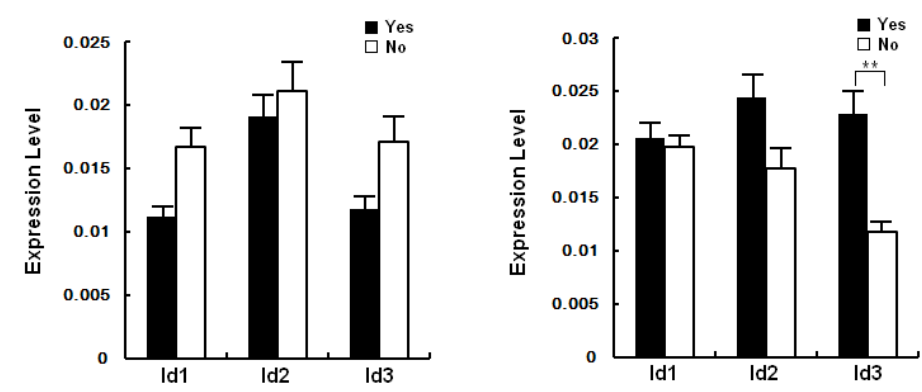

${ }^{*}$ Compared with the patients without the ultrasonic characteristics, $p<0.01$

Figure 4: Id-1, Id-2, and Id-3 mRNAs expressions in patients with or without ultrasonic characteristics. (A-E). Keloid-like, hyperechoic halo, posterior acoustic attenuation, microcalcification, and peripheral catheter expansion group. 
Citation: Shi H, Zhang L, Qu Y, Hou L, Wang L, et al. (2014) Correlation between Id Genes Expressions and Histological Grade, Sonographic Findings in Breast Cancer. J Cytol Histol S4: 005. doi:10.4172/2157-7099.S4-005

reported previously. Keloid-like nodule is one of the symptoms of malignant tumor, which probable have cancer cell infiltration and usually comes from hyperplasia of mammary gland small catheter and the surrounding connective tissues [26,27]. Hyperechoic halo is also an important indicator for identification of malignant tumors. The higher of the pathology grade is, the more obvious of the hyperechonic halo is $[25,28]$. In this study, we found that Id- 1 and Id-3 mRNA were highly expressed in patients with keloid-like and hyperechoic halo on ultrasonography $(\mathrm{p}<0.01)$, indicaitng Id-1 and Id-3 may be one of the genetic basis of the "keloid-like" imaging. However, no significant association between Id-2 and ultrasonic characteristics was found. Thus, further studies are still needed.

In conclusion, our results suggest that molecular biology behavior may be the basis for the pathological and sonographic characteristics of breast cancer. The use of breast ultrasound may be useful for predicting prognosis.

\section{Acknowledgements}

Thanks First Clinical College of Harbin Medical University for their patients cases provides, and all the authors who contributed to our study and article.

\section{References}

1. Ferlay J, Shin HR, Bray F, Forman D, Mathers C, et al. (2010) Estimates of worldwide burden of cancer in 2008: GLOBOCAN 2008. Int J Cancer 127: 2893-2917.

2. Yang L, Parkin DM, Ferlay J, Li L, Chen Y (2005) Estimates of cancer incidence in China for 2000 and projections for 2005. Cancer Epidemiol Biomarkers Prev 14: $243-250$

3. Linos E, Spanos D, Rosner BA, Linos K, Hesketh T, et al. (2008) Effects of reproductive and demographic changes on breast cancer incidence in China: a modeling analysis. J Natl Cancer Inst 100: 1352-1360.

4. Chuthapisith S, Eremin J, El-Sheemey M, Eremin O (2010) Breast cancer chemoresistance: emerging importance of cancer stem cells. Surg Oncol 19: 27-32.

5. Clatot F, Philippin-Lauridant G, Ouvrier MJ, Nakry T, Laberge-Le-Couteulx S, et al. (2009) Clinical improvement and survival in breast cancer leptomeningeal metastasis correlate with the cytologic response to intrathecal chemotherapy. J Neurooncol 95: 421-426.

6. Feyer PC, Steingraeber M (2012) Radiotherapy of Bone Metastasis in Breast Cancer Patients - Current Approaches. Breast Care (Basel) 7: 108-112.

7. Ouyang XS, Wang X, Ling MT, Wong HL, Tsao SW, et al. (2002) Id-1 stimulates serum independent prostate cancer cell proliferation through inactivation of p16(INK4a)/pRB pathway. Carcinogenesis 23: 721-725.

8. Fong S, Itahana Y, Sumida T, Singh J, Coppe JP, et al. (2003) Id-1 as a molecular target in therapy for breast cancer cell invasion and metastasis. Proc Natl Acad Sci U S A 100: 13543-13548.

9. Gupta GP, Perk J, Acharyya S, de Candia P, Mittal V, et al. (2007) ID genes mediate tumor reinitiation during breast cancer lung metastasis. Proc Natl Acad Sci U S A 104: 19506-19511.

10. Chen YH, Wu ZQ, Zhao YL, Si YL, Guo MZ, et al. (2012) FHL2 inhibits the Id3-promoted proliferation and invasive growth of human MCF-7 breast cancer cells. Chin Med J (Engl) 125: 2329-2333.
11. Mern DS, Hoppe-Seyler K, Hoppe-Seyler F, Hasskarl J, Burwinkel B (2010) Targeting Id 1 and Id 3 by a specific peptide aptamer induces E-box promoter activity, cell cycle arrest, and apoptosis in breast cancer cells. Breast Cancer Res Treat 124: 623-633.

12. Schoppmann SF, Schindl M, Bayer G, Aumayr K, Dienes J, et al. (2003) Overexpression of Id-1 is associated with poor clinical outcome in node negative breast cancer. Int J Cancer 104: 677-682.

13. Ture M, Tokatli F, Kurt I (2009) Using Kaplan-Meier analysis together with decision tree methods (C\&RT, CHAID, QUEST, C4. 5 and ID3) in determining recurrence-free survival of breast cancer patients. Expert Systems with Applications 36: 2017-2026.

14. McAllister SD, Christian RT, Horowitz MP, Garcia A, Desprez PY (2007) Cannabidiol as a novel inhibitor of Id-1 gene expression in aggressive breast cancer cells. Mol Cancer Ther 6: 2921-2927.

15. Itahana Y, Singh J, Sumida T, Coppe JP, Parrinello S, et al. (2003) Role of Id-2 in the maintenance of a differentiated and noninvasive phenotype in breast cancer cells. Cancer Res 63: 7098-7105.

16. Stighall M, Manetopoulos C, Axelson H, Landberg G (2005) High ID2 protein expression correlates with a favourable prognosis in patients with primary breast cancer and reduces cellular invasiveness of breast cancer cells. Int $J$ Cancer 115: 403-411.

17. Cao XL, Bao W, Zhu SG, Wang LH, Sun MH, et al. (2014) Contrast-enhanced ultrasound characteristics of breast cancer: correlation with prognostic factors. Ultrasound Med Biol 40: 11-17.

8. Knight R, Horiuchi K, Parker SH, Ratzer ER, Fenoglio ME (2002) Risk of needle-track seeding after diagnostic image-guided core needle biopsy in breast cancer. JSLS 6: 207-209.

19. Whitten TM, Wallace TW, Bird RE, Turk PS (1997) Image-guided core biopsy has advantages over needle localization biopsy for the diagnosis of nonpalpable breast cancer. Am Surg 63: 1072-1077.

20. Smetherman DH (2013) Screening, imaging, and image-guided biopsy techniques for breast cancer. Surg Clin North Am 93: 309-327.

21. Böcker W (2002) [WHO classification of breast tumors and tumors of the female genital organs: pathology and genetics]. Verh Dtsch Ges Pathol 86: 116-119.

22. Huh J-I, Charles R, Qiu T, Catena R, Calvo A, et al. (2005) Differentiation of mammary epithelial cells by 2-methoxyestradiol is associated with downregulation of Id-1 expression. Proc Amer Assoc Cancer Res 46: 262.

23. Park MJ, Joo BS, Lee JE, Kim HJ, Moon SE et al. (2010) Alendronate enhances osteoblastic differentiation with increased expression of Id-1 and Id-2 in preosteoblast cell line, MC3T3-E1. Korean Journal of Obstetrics and Gynecology 53: $274-281$

24. Stavros AT, Thickman D, Rapp CL, Dennis MA, Parker SH, et al. (1995) Solid breast nodules: use of sonography to distinguish between benign and malignant lesions. Radiology 196: 123-134.

25. Kim SH, Seo BK, Lee J, Kim SJ, Cho KR, et al. (2008) Correlation of ultrasound findings with histology, tumor grade, and biological markers in breast cancer. Acta Oncol 47: 1531-1538.

26. Mullinax K, Cohen JB (2004) Carcinoma en cuirasse presenting as keloids of the chest. Dermatol Surg 30: 226-228

27. Littrup PJ, Freeman-Gibb L, Andea A, White M, Amerikia KC, et al. (2005) Cryotherapy for breast fibroadenomas. Radiology 234: 63-72.

28. Kasami M, Uematsu T, Honda M, Yabuzaki T, Sanuki J, et al. (2008) Comparison of estrogen receptor, progesterone receptor and Her-2 status in breast cancer pre- and post-neoadjuvant chemotherapy. Breast 17: 523-527. 